IZA DP No. 6847

It's a Boy! Women and Non-Monetary Benefits from a Son in India

Laura Zimmermann

September 2012 


\title{
It's a Boy! Women and Non-Monetary Benefits from a Son in India
}

\author{
Laura Zimmermann \\ University of Michigan \\ and IZA
}

\section{Discussion Paper No. 6847 \\ September 2012}

\author{
IZA \\ P.O. Box 7240 \\ 53072 Bonn \\ Germany \\ Phone: +49-228-3894-0 \\ Fax: +49-228-3894-180 \\ E-mail: iza@iza.org
}

\begin{abstract}
Any opinions expressed here are those of the author(s) and not those of IZA. Research published in this series may include views on policy, but the institute itself takes no institutional policy positions.

The Institute for the Study of Labor (IZA) in Bonn is a local and virtual international research center and a place of communication between science, politics and business. IZA is an independent nonprofit organization supported by Deutsche Post Foundation. The center is associated with the University of Bonn and offers a stimulating research environment through its international network, workshops and conferences, data service, project support, research visits and doctoral program. IZA engages in (i) original and internationally competitive research in all fields of labor economics, (ii) development of policy concepts, and (iii) dissemination of research results and concepts to the interested public.
\end{abstract}

IZA Discussion Papers often represent preliminary work and are circulated to encourage discussion. Citation of such a paper should account for its provisional character. A revised version may be available directly from the author. 


\section{ABSTRACT \\ It's a Boy! \\ Women and Non-Monetary Benefits from a Son in India*}

Son preference is widespread in a number of developing countries. Anecdotal evidence suggests that women may contribute to the persistence of this phenomenon because they derive substantial long-run non-monetary benefits from giving birth to a son in the form of an improvement in their intra-household position. This paper tests this hypothesis in the Indian context. The results suggest that for the most part there is little evidence of substantial female benefits, and any positive impacts of having a son disappear after six months. This implies that the female-specific self-interest in a son is probably much lower than commonly assumed.

JEL Classification: $\quad$ D13, J12, J13, J16

Keywords: $\quad$ son preference, non-monetary benefits, bargaining power, intra-household allocation, India

Corresponding author:

Laura Zimmermann

University of Michigan

Department of Economics

611 Tappan St.

Ann Arbor, MI 48109

USA

E-mail: Ivzimmer@umich.edu

\footnotetext{
*I thank Raj Arunachalam, Rema Hanna, David Lam, Emily Oster, Rebecca Thornton and participants at the 2012 Population Association Annual Meeting, a Delhi School of Economics seminar and of the University of Michigan Informal Development Seminar for valuable comments and suggestions.
} 


\section{Introduction}

In a number of countries like China, India, South Korea and Taiwan, the number of girls relative to boys is unnaturally low (see e.g. Das Gupta et al. 2009). This son preference $^{1}$ has proven to be highly persistent in many developing countries over the last decades despite major changes like rising literacy and education levels. Economic research has suggested various different explanations for these patterns, including higher economic returns from a son than a daughter, family tastes for a certain sex composition of children, and special cultural traditions and practices which require having a son (see e.g. Rosenzweig and Schultz 1982, Rose 2000, Qian 2008, Almond et al. 2009).

In addition to these mechanisms, a channel that is receiving increasing attention is a potential mother-specific reason for son preference: Anecdotal evidence suggests that women in a number of developing countries derive substantial non-monetary benefits from giving birth to a son because a boy increases their intra-household bargaining position. Women are seen as having fulfilled their duty and are accepted as full household members after the birth of a boy, and thus become more fully involved in the household decision-making process (see e.g. Das Gupta et al. 2002). If women value this side-effect from having a boy, this may counteract or even outweigh some of the other incentives that may make women less likely to favor boys, such as their own experiences of growing up in an environment where social prestige depends on having male heirs.

The economics literature on this topic is still very sparse. In one of the few papers that focus specifically on this topic, $\mathrm{Li}$ and $\mathrm{Wu}$ (2011) find that having a first-born son in China does lead to improvements in the mother's bargaining power, suggesting that women do indeed benefit from giving birth to a boy. China is a very specific case in a number of respects, however, so it is unclear whether women-specific benefits from

\footnotetext{
${ }^{1}$ In this paper, son preference is defined as preferring a son to a daughter. The use of the term in this sense therefore includes a number of channels that may lead to this outcome, like economic returns as well as taste-based discrimination.
} 
having a son are important in other contexts as well.

In this paper, I therefore focus on testing the existence of female non-monetary benefits from having a son in the Indian context where son preference is widespread and female non-monetary benefits from a son are commonly believed to be high. I use two large cross-sectional datasets from 1998/99 and 2005 that are nationally representative of the Indian population. Because of endogeneity concerns in a society with skewed sex ratios, my main analysis focuses on first-born children who are at most six months old. I argue that for this restricted sample, the gender of a child is exogenous, and there is little time to change household behavior after the first child is born, for example by decreasing birth spacing intervals if the first child happens to be a girl. In consequence, families with a girl should have similar individual and household characteristics as families with a boy.

I find that having given birth to a boy rather than a girl has at best short-term benefits for the mother: Gender has no statistically significant impact on the mother's decision-making powers in the earlier dataset, and the positive impacts in the more recent dataset disappear for older children, suggesting that the non-monetary benefits from the birth of a son are short-lived. There is also little evidence for major improvements of the mother's intra-household position in other monetary or non-monetary ways, for example through more financial independence or more freedom in carrying out activities outside the house.

Overall, the results in this paper suggest that the non-monetary benefits for mothers from having a son in India are much less important than commonly assumed. While these benefits should be high and long-lasting according to anecdotal evidence, the results in this paper show that mothers do not benefit permanently from having a son. Female-specific non-monetary incentives for having a son therefore are unlikely to be of high importance in the persistence of son preference at least in the Indian context. 
The rest of this paper is structured as follows: Section 2 provides some background information on son preference and advanced hypotheses in the Indian context. Section 3 explains the empirical strategy and presents descriptive statistics. Section 4 focuses on the main results as well as some extensions. Section 5 concludes.

\section{Son Preference in India}

Sex ratios in India, usually reported as the number of girls per 1000 boys in the 0-6 year age group, are skewed towards males and have been falling over the past decades both at the national level and in many Indian states (see e.g. John 2011). Unnaturally low numbers of females tend to be concentrated in North-West, North-Central and West India, although the national sex ratio has also been too low for the last two censuses. ${ }^{2}$

These patterns strongly suggest that son preference is an important concern in India. Especially the continuing fall of sex ratios over the years has attracted a lot of academic research on the potential underlying causes of this preference for boys over girls. In general, researchers focus on two main channels: economic and cultural considerations. With respect to economic considerations, boys may be a better investment if they have a higher probability of earning income and are expected to provide shelter and financial support for their parents later in life. Male labor force participation in India generally is significantly higher than that of women, so having a son may indeed lead to better old-age support for the parents (see e.g. Rosenzweig and Schultz 1982, Rose 2000, Chung and Das Gupta 2007). Especially in North India, on the other hand, girls are traditionally seen as ceasing to be part of the family when they marry, so that

\footnotetext{
2" Too low" here refers to being outside the estimated India-specific confidence intervals for the natural sex ratio at birth, which is a lower bound of the 0-6 year sex ratio since girls have a natural survival advantage (see e.g. Waldron 1983). According to Bhat and Zavier (2007), the natural sex ratio confidence interval is 943-971 female births per 1000 male births, whereas Srinivasan and Bedi (2009) put it at 932-965.
} 
a daughter's earnings benefit her husband's family instead. Additionally, dowries are paid in large parts of the country when a girl marries, and, although its existence is still debated in the literature, anecdotal evidence suggests that dowry inflation is an important concern in India and the broader region (see e.g. Rao 1993, Anderson 2003, Arunachalam and Logan 2008).

Cultural considerations are also often advanced as an important factor for son preference in India. Parents may prefer sons for a number of reasons: Some religious rituals like lighting the funeral pyre of the parents, for example, need to be performed by a son. Women also traditionally cannot inherit property in large parts of the country so that parents need a male heir to pass on their land and family possessions (see e.g. Dyson and Moore 1983, Almond et al. 2009).

Most of these potential reasons implicitly focus on household behavior and tastes and therefore assume that households are monolithic entities with a single utility function, which collectively prefer sons over daughters. While this may be a good way to describe overall household preferences, the channels that lead to individual members' son preference are understudied. Women of childbearing age are an especially interesting case in this respect: Being women themselves and having grown up in surroundings where son preference is widespread, one could assume that these women would practice less discrimination against girls in their own fertility and sex composition decisions. Similarly, with modernizing influences of increased female education and labor force participation that increase females' economic contributions to the household and their bargaining power, one might expect women to use their increased say in household matters to practice less preferential treatment among their own children. Empirical results demonstrate, however, that this is not always the case: Sex ratios continue to fall even though factors like female educational attainment have improved markedly over the years, and papers like Das Gupta (1987) show that educated mothers are far 
more efficient in gender discrimination than women without education.

A potentially important reason for this empirical pattern may be that women across India benefit from the birth of a son in additional ways, for example through increased decision-making powers in the household. Research on the family and kinship system prevailing in Northern India suggests, for example, that non-monetary benefits may be an important explanation for son preference among women (see e.g. Kishor 1993, Das Gupta et al. 2002, Kaur 2008): The position of women in the household changes importantly over the life cycle. Women in this region are typically seen as ceasing to be members of their parents' family when they marry and in general cannot inherit family property. They have a weak position in the household that they enter as brides, even though women make important contributions to the household by working on the fields or managing the household chores. The birth of a son, however, raises the social prestige of the family and leads to increased respect for the mother of the child. Furthermore, husbands typically start withdrawing from being involved in family decision-making as they get older, and women start taking over the management of the household with the support of their grown-up sons (Rahman, Foster and Menken 1992, Das Gupta 1995). This pattern, papers like Das Gupta et al. (2002) suggest, leads to a preference for sons, as sons can provide support and protection for their mothers. ${ }^{3}$

The North Indian kinship system therefore seems to facilitate women's preference for boys as having a son increases a woman's bargaining power in the household: While young women have little say in household matters that are typically decided by the mother-in-law or other household members, women can take over the management of the household with the support of their grown-up sons. Das Gupta et al. (2002) therefore argue that a woman may work to ensure the loyalty of her sons by spoiling

\footnotetext{
${ }^{3}$ These papers often suggest that the pressure to have sons is lower in South India since family systems tend to be more flexible and allow women a more important role in society. In results not reported in this paper, I find no regional patterns of the impact of having a son on the female intrahousehold position.
} 
them or letting them see how other household members mistreat her. Since sons are the later supporters of the household and therefore the key figure in deciding on the future allocation of resources within the household, household members may want to stay on the child's good side. The presence of a loyal son therefore increases a woman's bargaining power, which she can use to take over household responsibilities.

But even right after the child's birth, non-monetary benefits for the mother seem to be substantial since the birth of a son typically leads to increased acceptance of a woman by other household members and the society at large. A son often increases a family's social prestige, and women can be seen as having fulfilled the duty of carrying on the family line. Women in North India are often called X's mother, and change their name after the birth of a son. This reflects an increased respect for the mother of the child (see for example Das Gupta 2009). As a way of demonstrating a new level of acceptance after the birth of a son, other household members may willingly transfer some of their responsibilities to the woman. On the other hand, anecdotal evidence suggests that women without sons are often the target of gossip or snide remarks in their village.

Anecdotal evidence therefore predicts that the woman's position in the household should improve after the birth of a son, for example through an increased say in household decision-making. These improvements should be long-lasting as well, with some benefits already occurring right after the birth of the child, and additional benefits setting in once the child is older.

In this paper, I test the existence of this channel by focusing on first-born children that are at most 12 months old. If the outlined hypothesis is correct, the mother of a young son should have a significantly better position in the household than a woman with a daughter. The empirical strategy used to estimate this effect in a society with heavily skewed sex ratios is discussed in the next section. 


\section{Empirical Strategy and Summary Statistics}

The empirical analysis in this paper makes use of the National Family and Health Surveys (NFHS) of 2005 and 1998/99, which are representative cross-sectional datasets for India. ${ }^{4}$ NFHS datasets include a household survey, collecting information on all members of the household, and a more detailed survey administered to all women aged 15-49. The women's questionnaire has information on the complete birth history of a woman as well as questions on decision-making powers and women's position within the household.

Various papers have documented that in India, as well as in other countries with son preference, gender is correlated with birth order (see e.g. Chen et al. 2010, Jayachandran and Kuziemko 2011, Lee 2008). Particularly, the sex of a child tends to be within the naturally expected bounds at low birth orders and especially the first birth, since even in the presence of son preference parents usually want more than one child (Almond et al. 2009, Bhalotra and Cochrane 2010). At higher parities, on the other hand, sex ratios become more skewed towards boys, which is thought to be a combination of sex-selective abortion and, in the Indian context, excess female mortality.

This pattern presents problems for the identification of the causal effect of child gender on the mother's position within the household. Ideally, we would like to estimate the following regression for all women with children:

$$
y_{i}=\alpha+\text { Bmale }_{i}+\epsilon_{i}
$$

where $y$ is a decision-making variable for woman $i$, and male is an indicator variable for whether a woman has a boy. The coefficient of interest is $\beta$, but in the presence of son preference, male will be correlated with the error term, even when controlling for birth order. In order to identify the causal effect of child gender on the mother's

\footnotetext{
${ }^{4}$ Decision-making questions do not appear in the NFHS dataset from 1992/93.
} 
position within the household, I therefore restrict my sample to first-born children, where the sex of the child is arguably exogenous. ${ }^{5}$ This research strategy has been used in some other papers in the literature (see for example Chen et al. 2010, Barcellos et al. 2011).

A related endogeneity concern is that households will practice differential stopping rules depending on the sex composition of their children (see for example Jensen 2002). Specifically, a family may keep having children until the desired number of sons is reached. This implies that the sex of the first child may be correlated with other factors like the number of children, birth intervals or household income if parents try to have a son after the first child turned out to be a girl. Without controlling for all potential intervening factors that may have an independent influence on the woman's position in the household, the estimate of $\beta$ will therefore still be biased.

In consequence, I further limit my sample to women who only have one child and who, in order to circumvent potential endogeneity concerns about differential birth spacing correlated with the gender of the child, have not had time to have a second child. There is a trade-off between sample size and bias in deciding on the appropriate cutoff. The older we allow the first child to be, the larger the sample size of women who fall into this category, but the higher is the probability that a woman will have had a second birth. For the main part of my analysis, I focus on first-born children who are 0-6 months old, although I also conduct robustness tests that also look at children that are up to 12 months old. This strategy is also used in Barcellos et al. (2011) in their analysis of differential treatment of boys and girls, although they use less conservative age cutoffs of 12 and 24 months.

Table 1 presents summary statistics for the main sample used for the empirical

\footnotetext{
${ }^{5}$ I also restrict the sample to non-multiple births only in order to ensure that we cleanly measure the impact of the child's gender on women's position in the household. Multiple births may have additional effects.
} 
analysis for both datasets. Women for whom the first child is a son are similar to women who have a daughter in terms of characteristics like household size, the household head's age, religion, and caste in both surveys. ${ }^{6}$ Women in the two groups also have no significantly different probability of currently being pregnant. This alleviates concerns about women with a girl becoming pregnant sooner than women with a boy in the sample used for analysis, which otherwise could cause differences in household decision-making powers. Boys and girls are also of the same age on average, so that any differences in women's position in the household are not driven by age differences of their children.

Unfortunately, however, women with boys and girls are not balanced on the mother's years of education and, for 2005, on mother's age, which are statistically significantly different at the 5 percent level, although the differences are not large in absolute terms in both cases. Women who have a first-born son of at most six months are more educated in 2005, but slightly less educated in 1998/99. In 2005, they also are slightly older than women with first-born daughters of similar age. ${ }^{7}$

The NFHS includes a couple of variables that can be used to measure a woman's decision-making powers in the household. Unfortunately, the questions asked differ between the two surveys, so the empirical results are not directly comparable. In 2005, women are asked to name the person who has the last say in their own health care, large purchases, daily purchases, visiting family and about what to do with the husband's money. In 1998/99, women are asked to name the person who has the last say in what to cook, in obtaining health care (in general, not just for herself), in purchasing jewelry,

\footnotetext{
${ }^{6}$ The NFHS does not collect income information, but constructs a wealth index by principal component analysis from asset information. There are no statistically significant differences for this wealth index between families with a boy and families with a girl in 2005 and 1998/99, either.

${ }^{7}$ The overall age and education distributions of mothers with daughters and sons look very similar, however (results not reported). I also include the mother's age and years of education in my regressions to control for this difference in characteristics that could potentially bias my results.
} 
and in deciding whether the respondent stays with family. ${ }^{8}$ The answer categories are either the respondent on her own, the respondent jointly with her husband, the husband on his own, or someone else. In 1998/99, an additional category is that the respondent decides jointly with someone else in the household.

These outcomes will be used for the main analysis of this paper. For each decisionmaking question, I construct a female decision-making indicator variable that is equal to 1 if the woman either has sole or joint decision-making power with her husband and is 0 otherwise. ${ }^{9}$ Additionally, I create a decision-making index variable from the individual decision-making questions by principal component analysis and standardize it by subtracting the mean and dividing by the standard deviation. This allows a more meaningful interpretation of regression coefficients as standard deviations.

The surveys also include information on other outcomes, for example on whether the woman has her own money, whether she has a savings account and whether she is allowed to go to the market, a health facility and somewhere outside the village or community on her own, with someone else's permission only, or not at all. These outcome variables proxy for improvements in the position of a woman in the household that go beyond decision-making powers.

I estimate the effect of child gender on the woman's position in the household by using a linear probability model. Given that the sample is not balanced on some observable characteristics, I control for a number of variables in my regressions. Those include household size, mother's age and the age of the household head, indicator variables for living in a rural area and for each year of mother's schooling, indicator

\footnotetext{
${ }^{8} \mathrm{~A}$ question about decision-making about money is missing for a large proportion of the relevant sample and is therefore ignored in this analysis.

${ }^{9}$ This definition minimizes the difference between the two samples in terms of the answering categories. Results are qualitatively the same if the joint decision-making power with someone else in the household in the 1998/99 survey is included as well. In results not reported here, I split up decisionmaking into joint and sole decision-making powers. There are no statistically significant impacts for sole female decision-making powers. The main results of this paper are qualitatively similar to the joint decision-making results.
} 
variables for being Hindu, Muslim, a member of the scheduled castes or scheduled tribes (SC and ST, respectively), and for being currently pregnant. I also include state fixed effects.

\section{Results}

\subsection{Main Results}

Tables 2 and 3 present the main results of the impact of the child's gender on the mother's decision-making powers in the household, both with and without control variables. Table 2 uses the NFHS 1998/99 sample, whereas Table 3 reports results for the NFHS 2005 dataset.

Table 2 shows that women do not seem to benefit from having a son rather than a daughter in terms of increased decision-making power in 1998/99: The estimated impacts of a son on any of the four decision-making categories as well as for the created index are never statistically significantly different from zero in any specification. The coefficients are typically relatively small in absolute magnitude, and are often even negative, suggesting that, although not significant, having a son is associated with less decision-making power for the mother than having a daughter.

Table 3 shows the corresponding results for the 2005 sample. In contrast to Table 2 , women do seem to benefit from having a son rather than a daughter in this case: Having a boy is associated with an about 4 percentage points higher probability of having a say in one's own health care, and an about 7 percentage points higher probability of being involved in decisions concerning large purchases. The probability of having a say in decisions about family visits increases by about 4.6 percentage points if the child is a boy. The coefficients for both large purchases and family visits are statistically significant at at least the 5 percent level, whereas the coefficient for own health care is 
only statistically significant at the 10 percent level once I include the control variables. The coefficients on the other two categories of decision-making, daily purchases and husband's money, are statistically insignificant, and the magnitude of the husband's money coefficient is basically zero. With a standardized index of the decision-making variables, decision-making increases by 0.18 standard deviations if the child is a son. The inclusion of control variables typically lowers the magnitude of the estimated coefficients a bit, suggesting that their inclusion is important, but the qualitative pattern remains the same.

Both Tables 2 and 3 focus on a sample of 0-6 month old children. The cutoff of the child's age at six months is arbitrary and was designed to balance the two goals of large sample size and cleaner identification by giving households little time to reoptimize and have a second child. In order to analyze whether there is some evidence of dynamic effects with the child's age, Tables 4 and 5 reproduce the results of the linear probability models with control variables from Tables 2 and 3 for samples of children aged 0-3 months, 4-6 months, 7-9 months, and 10-12 months separately for all the decision-making questions and the created index.

Table 4 shows that as in Table 2, there is no evidence that having a boy significantly improves the decision-making powers of the mother relative to having a daughter. The coefficients tend to be larger in absolute magnitude for older children than for younger ones and, in contrast to Table 2, most of them are positive, but almost all of the coefficients are statistically significantly different from zero. The only estimated coefficient that is statistically significant at conventional levels is the impact of having a boy for family visits in the sample of 0-3 month olds: Having a son is associated with an about 5 percentage point lower probability of making decisions about staying with family. Overall, Table 4 therefore suggests again that women with sons do not have a significantly better intra-household position than women with girls. 
Table 5 reveals that for the most part the results in Table 3 for the 2005 sample were driven by the impacts of child gender on female decision-making power for women with 4-6 months old children. Both economic and statistical significance are highest for mothers with children in this age group, with the estimated coefficients being similar in magnitude and statistical significance to the results in Table 3. The estimated coefficients are much smaller for the younger children (at most 3 months old) and statistically insignificant with the exception of the coefficient for the index, which is significant at the 10 percent level. The coefficients for children older than 6 months are typically small and, except for the coefficient on large purchases for 10-12 month old children, statistically insignificant. All coefficients for the oldest age group of children (10-12 months) go into the wrong direction with being negative.

While these patterns cannot strictly be interpreted as dynamic effects, since they come from cross-sectional data rather than from panel observations, they are consistent with the idea that it may take some time for the positive effects of having a boy to feed through to improvements in decision-making powers since the highest effects are observed for mothers of 4-6 month old children. At the same time, these positive effects seem to wear off after the child is half a year old. For children that are older than six months, the gender of the child is no longer an important predictor of female decisionmaking power. This seems to point to some version of a honeymoon effect where women can reap benefits in intra-household decision-making for the first six months, after which the household seems to re-optimize until the child gender is unimportant for decision-making powers.

Overall, the results from Tables 2 to 5 suggest that there are no long-run female non-monetary benefits from giving birth to a son rather than a daughter. While there is no real evidence for any gender-specific impacts in the 1998/99 sample, there are some positive effects of having a son for decision-making power in the 2005 sample 
for mothers of young children. These benefits disappear for mothers of older children, however, suggesting that any improvements in a woman's intra-household position are short-lived.

The differences in the patterns between the two datasets could be driven by the differences in the specific decision-making questions asked as well as by other differences between the two surveys. Given that the two surveys are only about six years apart, it seems possible but relatively unlikely that there would have been significant changes in intra-household dynamics in-between the surveys that would have prompted women to respond differently in the two surveys. As Table 1 shows, the samples in the two datasets are relatively similar to each other, suggesting that the differences are also unlikely to be driven by big differences in sample composition.

\subsection{Additional Analysis}

The main results analyzed the impact of child gender on female decision-making powers within the household. Household members may show their increased acceptance of the mother after the birth of a son in additional ways that go beyond increased responsibilities in the household, however. Table 6 therefore looks at additional outcome variables that proxy for a woman's position in the household in the 2005 sample of 0-6 month olds $^{10}$, namely indicator variables for whether the woman has access to some money of her own, and whether she has a savings account. Panel A also includes indicator variables for three questions relating to the woman's ability to go to the market, a health facility, and to places outside the village without having to ask for the permission of other household members. The indicator variables are 0 if the woman has to ask for the permission or is not allowed to go at all. Panel B looks at changes in these last

\footnotetext{
${ }^{10}$ A similar analysis for the $1998 / 99$ dataset again has no statistically significant impacts and is omitted for brevity. There no interesting patterns for the corresponding analysis to Table 5, either.
} 
three variables where the indicator variable is equal to 1 if the woman has to ask for the permission of another household member to go somewhere, and is 0 otherwise.

The results in Table 6 demonstrate that the improvements in the woman's position in the household in the 2005 sample are confined to increases in decision-making power and for the most part do not translate into more financial or individual independence. Once we include control variables, the only coefficient that is statistically significant at conventional levels is the coefficient for having a savings account. The probability of having an account is 2.6 percentage points higher for women with a son than for women with a daughter, and the effect is statistically significant at the 10 percent level. The coefficients on the personal freedom questions generally seem to suggest a decrease in having to ask for the permission of other household members of about 1 percentage point for the market and health facility questions, and a similar increase in being able to go without someone else's permission, but the coefficients are all statistically insignificant. The estimated coefficient for having access to money of her own is even negative, although again statistically insignificant.

Overall, Table 6 shows that there seem to be few changes in financial and personal independence that depend on the gender of the child. The main benefits of having a boy for a woman are therefore the increases in decision-making in various household decisions, although, as Table 5 showed, those too seem to be short-lived. ${ }^{11}$

\section{Conclusion}

This paper has analyzed whether women of child-bearing age gain from giving birth to a son in non-monetary terms through an improved position in the household. As the results show, having a young son rather than a daughter of the same age at best

\footnotetext{
${ }^{11}$ The results from Table 5 do not differ statistically along dimensions like region, religion, caste, living in a rural area, or relationship to the household head (not reported here).
} 
leads to a short-term improvement in decision-making power, but even then does not affect the freedom to perform more day-to-day activities without having to ask for the permission of other household members. There is only a significant impact in one of the two analyzed datasets, and even in this dataset the benefits disappear for children who are older than six months.

These effects may be a lower bound of the improvement of a woman's position in the household after the birth of a son if some changes in household decision-making take more time than the up to 12 months considered in this paper. Increased bargaining power due to a son's loyalty to his mother may lead to additional increases in intrahousehold powers once the child is old enough to witness how his mother is being treated by other family members, for example. So while the empirical analysis in this paper suggests that the non-monetary benefits for women from having a son are very limited, it may not fully capture all the positive effects that women experience after the birth of a boy. More research is needed to analyze this issue further and to better take into account more long-term benefits that cannot be focused on here because of endogeneity concerns.

Nevertheless, the current results seem to suggest that women may not have a significant non-monetary self-interest in giving birth to a son rather than a daughter. This is very different from commonly provided anecdotal evidence that argues that women derive substantial long-term benefits from having a boy, and existing research that shows the importance of such an effect in China. Especially in a world where more female decision-making power is increasingly seen as desirable by both policymakers and women themselves, it is important to know that female bargaining power does not seem to harm the survival chances of girls in all contexts: Since women in India do not seem to majorly benefit from the birth of a son through an improvement in their position in the household, they do not seem to have to trade off their own future benefits 
for having a daughter rather than a son. This implies that it should be possible for policymakers to encourage both female decision-making and discourage son preference simultaneously without having to worry too much about the interaction effects of these two policies. 


\section{References}

[1] Almond, D., Edlund, L., and Milligan, K. Son Preference and the Persistence of Culture: Evidence from Asian Immigrants to Canada, NBER Working Paper 15391, 2009.

[2] Anderson, S. Why Dowry Payments Declined with Modernization in Europe but Are Rising in India, Journal of Political Economy, 111(2): 269-310, 2003.

[3] Arunachalam, R. and Logan, Trevon D. Is There Dowry Inflation in South Asia? Working Paper, 2008.

[4] Barcellos, S.H., Carvalho, L. and A. Lleras-Muney. Child Gender and Parental Investments in India - Are Boys and Girls Treated Differently? RAND Working Paper, 2011.

[5] Bhalotra, S. and Cochrane, T. Where Have All the Young Girls Gone? Identification of Sex Selection in India, IZA Discussion Paper 5381, 2010.

[6] Bhat, P N M. and Zavier, A J F. Factors Influencing the Use of Prenatal Diagnostic Techniques and the Sex Ratio at Birth in India, Economic and Political Weekly, 2292-2303, 2007.

[7] Chen, Y., Chen, S.H. and Liu, J. Separate Effects of Sibling Gender and Family Size on Educational Achievements - Methods and First Evidence from Population Birth Registry. Working Paper, 2010.

[8] Chung, W. and Das Gupta, M. Why Is Son Preference Declining in South Korea? The Role of Development and Public Policy, and the Implications for China and India, The World Bank Development Research Group, Policy Research Working Paper 4373, 2007.

[9] Das Gupta, M. Selective Discrimination against Female Children in Rural Punjab, Population and Development Review 13: 77-100, 1987.

[10] Das Gupta, M., Zhenghua, J., Bobua, L., Zbenming, X., Chung, W. and Bae, H. Why Is Son Preference So Persistent in East and South Asia?, The World Bank Development Research Group, Policy Research Working Paper 2942, 2002.

[11] Das Gupta, M., Chung, W., and Shuzhuo. Is There an Incipient Turnaround in Asia's 'Missing Girls' Phenomenon? The World Bank Development Research Group, Policy Research Working Paper 4846, 2009.

[12] Dyson, T. and Moore, M. On Kinship Structure, Female Autonomy, and Demographic Behavior in India, Population and Development Review, 9(1): 35-60, 1983. 
[13] Jayachandran, S. and Kuziemko, I. Why Do Mothers Breastfeed Girls Less Than Boys? Evidence and Implications for Child Health in India. Quarterly Journal of Economics, 126: 1485-1538, 2011.

[14] Jensen, R. Equal Treatment, Unequal Outcomes? Generating Gender Inequality through Fertility Behavior, unpublished manuscript, John F. Kennedy School of Government, Harvard University, 2002.

[15] John, M. E. Census 2011: Governing Populations and the Girl Child, Economic and Political Weekly, 46(16): 10-12, 2011.

[16] Kaur, R. Dispensable Daughters and Bachelor Sons: Sex Discrimination in North India, Economic and Political Weekly, 109-114, 2008.

[17] Kishor, S. 'May God Give Sons to All': Gender and Child Mortality in India, American Sociological Review, 58(2): 247-265, 1993.

[18] Lee, J. Sibling Size and Investment in Children's Education: An Asian Instrument, Journal of Population Economics, 21(4): 855-875, 2008.

[19] Qian, N. Missing Women and the Price of Tea in China: The Effect of Sex-Specific Earnings on Sex Imbalance, The Quarterly Journal of Economics, 123(3): 12511285, 2008.

[20] Rahman, O., Foster, A., and Menken, J. Older Widow Mortality in Rural Bangladesh, Social Science and Medicine, 34(1): 89-96, 1992.

[21] Rao, V. The Rising Price of Husbands: A Hedonic Analysis of Dowry Increases in Rural India, Journal of Political Economy, 101(4): 666-677, 1993.

[22] Rose, E. Gender Bias, Credit Constraints and Time Allocation in Rural India. The Economic Journal, 110(465):738-758, 2000.

[23] Rosenzweig, M.R. and T.P. Schultz. Market Opportunities, Genetic Endowments, and Intrafamily Resource Distribution: Child Survival in Rural India. American Economic Review. 72(4): 803-815, 1982.

[24] Srinivasan, S., and Bedi, A. S. Tamil Nadu and the DIagonal Divide in Sex Ratios, Economic and Political Weekly, 56-63, 2009.

[25] Waldron, I. The Role of Genetic and Biological Factors in Sex Differences in Mortality, in Lopez, A. D. and Ruzicka, L.T., eds, Sex Differentials in Mortality: Trends, Determinants, and Consequences, New York, NT: Department of Demography, 141-164, 1983. 
Table 1: Summary Statistics

\begin{tabular}{|c|c|c|c|c|c|c|}
\hline & \multicolumn{3}{|c|}{ 1998/99 } & \multicolumn{3}{|c|}{2005} \\
\hline & boy & girl & $\begin{array}{l}\mathrm{p} \text {-value of } \\
\text { difference }\end{array}$ & boy & girl & $\begin{array}{l}\mathrm{p} \text {-value of } \\
\text { difference }\end{array}$ \\
\hline $\mathrm{N}$ & 1,008 & 997 & & 963 & 955 & \\
\hline child's age & 3.35 & 3.35 & 0.99 & 3.36 & 3.30 & 0.46 \\
\hline household size & 7.45 & 7.53 & 0.64 & 6.59 & 6.76 & 0.23 \\
\hline mother's age & 20.96 & 21.08 & 0.44 & 22.18 & 21.80 & 0.04 \\
\hline household head age & 47.97 & 47.24 & 0.28 & 46.61 & 45.98 & 0.36 \\
\hline years of schooling mother & 3.51 & 3.67 & 0.05 & 4.08 & 3.87 & 0.02 \\
\hline Hindu & 0.76 & 0.77 & 0.56 & 0.74 & 0.74 & 0.72 \\
\hline Muslim & 0.13 & 0.12 & 0.59 & 0.13 & 0.13 & 0.74 \\
\hline $\mathrm{SC}$ & 0.18 & 0.16 & 0.31 & 0.17 & 0.17 & 0.89 \\
\hline $\mathrm{ST}$ & 0.14 & 0.13 & 0.44 & 0.14 & 0.14 & 0.84 \\
\hline currently pregnant & 0.00 & 0.00 & 0.41 & 0.005 & 0.003 & 0.49 \\
\hline
\end{tabular}

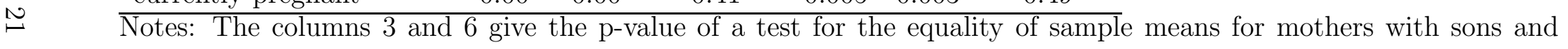
mothers with daughters. Datasets are the NFHS 1998/99 and the NFHS 2005 surveys. 
Table 2: The Impactt of Child Gender on Household Decision-Making (1998/99)

\begin{tabular}{lccccc} 
& cooking & health care & jewelry & family visits & index \\
\hline son (no controls) & 0.0109 & -0.0010 & -0.0104 & -0.0295 & -0.0272 \\
& $(.0222)$ & $(.0215)$ & $(.0201)$ & $(.0203)$ & $(.0447)$ \\
R-squared & 0.0001 & 0.0000 & 0.0001 & 0.0011 & 0.0002 \\
& & & & & \\
son (with controls) & 0.0096 & 0.0044 & -0.0038 & -0.0198 & -0.0113 \\
& $(.0207)$ & $(.0204)$ & $(.0193)$ & $(.0193)$ & $(.0412)$ \\
R-squared & 0.172 & 0.1367 & 0.1185 & 0.1358 & 0.1904 \\
& & & & & \\
$\mathrm{~N}$ & 2005 & 2005 & 2004 & 2002 & 2002 \\
mean & 0.5481 & 0.3636 & 0.2819 & 0.2917 & 0.0000 \\
\hline Notes: ${ }^{* * *} \mathrm{p}<0.01,{ }^{* *} \mathrm{p}<0.05,{ }^{*} \mathrm{p}<0.1$ & & &
\end{tabular}

Outcome variables in columns 1 to 4 are indicator variables equal to one if a woman has either joint or sole decisionmaking power in a given category. The index for each panel was created by principal component analysis, using the four indicator variables as imputs, and then standardized by subtracting the mean and dividing by the standard deviation.

Control variables are: household size, mother's age and the age of the household head, indicator variables for living in a rural area and for each year of mother's schooling, indicator variables for being Hindu, Muslim, a member of the scheduled castes or scheduled tribes (SC and ST, respectively), and for being currently pregnant. I also include state fixed effects. 
Table 3: The Impact of Child Gender on Household Decision-Making (2005)

own health care large purchases daily purchases family visits husband money index

\begin{tabular}{|c|c|c|c|c|c|c|}
\hline son (no controls) & $\begin{array}{l}0.0424^{*} \\
(0.0230)\end{array}$ & $\begin{array}{c}0.0750^{* * *} \\
(0.0236)\end{array}$ & $\begin{array}{c}0.0319 \\
(0.0238)\end{array}$ & $\begin{array}{c}0.0490^{* *} \\
(0.0235)\end{array}$ & $\begin{array}{l}-0.0067 \\
(0.0231)\end{array}$ & $\begin{array}{c}0.1746^{* * *} \\
(0.0523)\end{array}$ \\
\hline R-squared & 0.0018 & 0.0057 & 0.001 & 0.0024 & 0.0001 & 0.0076 \\
\hline son (with controls) & $\begin{array}{l}0.0394^{*} \\
(0.0221)\end{array}$ & $\begin{array}{c}0.0693^{* * *} \\
(0.0224)\end{array}$ & $\begin{array}{c}0.0264 \\
(0.0223)\end{array}$ & $\begin{array}{c}0.0461^{* *} \\
(0.0218)\end{array}$ & $\begin{array}{c}0.0003 \\
(0.0227)\end{array}$ & $\begin{array}{c}0.1822^{* * * *} \\
(0.0516)\end{array}$ \\
\hline R-squared & 0.1233 & 0.1482 & 0.1685 & 0.1819 & 0.0862 & 0.0947 \\
\hline $\begin{array}{l}\mathrm{N} \\
\text { mean }\end{array}$ & $\begin{array}{c}1839 \\
0.5759\end{array}$ & $\begin{array}{c}1772 \\
0.4458\end{array}$ & $\begin{array}{c}1758 \\
0.4846\end{array}$ & $\begin{array}{c}1788 \\
0.5593\end{array}$ & $\begin{array}{c}1546 \\
0.7083\end{array}$ & $\begin{array}{c}1451 \\
0.0000\end{array}$ \\
\hline
\end{tabular}

Outcome variables in columns 1 to 5 are indicator variables equal to one if a woman has either joint or sole decisionmaking power in a given category. The index for each panel was created by principal component analysis, using the five indicator variables as imputs, and then standardized by subtracting the mean and dividing by the standard deviation.

Control variables are: household size, mother's age and the age of the household head, indicator variables for living in a rural area and for each year of mother's schooling, indicator variables for being Hindu, Muslim, a member of the scheduled castes or scheduled tribes (SC and ST, respectively), and for being currently pregnant. I also include state fixed effects. 
Table 4: The Impact of Child Gender on Decision-Making over Time (1998/99)

\begin{tabular}{lccccc} 
& cooking & health care & jewelry & family visits & index \\
\hline 0-3 months & 0.0033 & -0.0129 & -0.0367 & $-0.0479^{*}$ & -0.0763 \\
& $(.0299)$ & $(.0300)$ & $(.0287)$ & $(.0286)$ & $(.0614)$ \\
4-6 months & 0.0273 & 0.0259 & 0.0331 & 0.0119 & 0.0687 \\
& $(.0291)$ & $(.0287)$ & $(.0265)$ & $(.0267)$ & $(.0564)$ \\
$7-9$ months & 0.0153 & 0.0155 & 0.0347 & 0.0100 & 0.0545 \\
& $(.0337)$ & $(.0333)$ & $(.0321)$ & $(.0310)$ & $(.0663)$ \\
10-12 months & 0.0276 & 0.0339 & 0.0142 & 0.0111 & 0.0574 \\
& $(.0337)$ & $(.0361)$ & $(.0344)$ & $(.0348)$ & $(.0719)$ \\
\hline
\end{tabular}

Notes: $* * * \mathrm{p}<0.01,{ }^{* *} \mathrm{p}<0.05,{ }^{*} \mathrm{p}<0.1$

Outcome variables in columns 1 to 4 are indicator variables equal to one if a woman has either joint or sole decisionmaking power in a given category. The index for each panel was created by principal component analysis, using the four indicator variables as imputs, and then standardized by subtracting the mean and dividing by the standard deviation.

Control variables are: household size, mother's age and the age of the household head, indicator variables for living in a rural area and for each year of mother's schooling, indicator variables for being Hindu, Muslim, a member of the scheduled castes or scheduled tribes (SC and ST, respectively), and for being currently pregnant. I also include state fixed effects. 
Table 5: The Impact of Child Gender on Decision-Making over Time (2005)

\begin{tabular}{|c|c|c|c|c|c|c|}
\hline & own health care & large purchases & daily purchases & family visits & husband money & index \\
\hline \multirow[t]{2}{*}{ 0-3 months } & .0060 & .0475 & .0192 & .0310 & -.0035 & $.1373^{*}$ \\
\hline & $(.0309)$ & $(.0311)$ & $(.0309)$ & $(.0306)$ & $(.0322)$ & $(.0728)$ \\
\hline \multirow[t]{2}{*}{ 4-6 months } & $.0751^{* *}$ & $.0906^{* * *}$ & .0343 & $.0633^{* *}$ & .0078 & $.2308^{* * *}$ \\
\hline & $(.0325)$ & $(.0331)$ & $(.0329)$ & $(.0315)$ & $(.0329)$ & $(.0758)$ \\
\hline \multirow[t]{2}{*}{ 7-9 months } & .0245 & .0177 & .0387 & $.0707 * *$ & .0107 & .0545 \\
\hline & $(.0322)$ & $(.0321)$ & $(.0319)$ & $(.0312)$ & $(.0321)$ & $(.0749)$ \\
\hline 10-12 months & $(.0341)$ & & $(.0337)$ & & $(.0340)$ & $(.0756)$ \\
\hline
\end{tabular}

Notes: ${ }^{* * *} \mathrm{p}<0.01,{ }^{* *} \mathrm{p}<0.05,{ }^{*} \mathrm{p}<0.1$

Outcome variables in columns 1 to 5 are indicator variables equal to one if a woman has either joint or sole decisionmaking power in a given category. The index for each panel was created by principal component analysis, using the five indicator variables as imputs, and then standardized by subtracting the mean and dividing by the standard deviation.

Control variables are: household size, mother's age and the age of the household head, indicator variables for living in a rural area and for each year of mother's schooling, indicator variables for being Hindu, Muslim, a member of the scheduled castes or scheduled tribes (SC and ST, respectively), and for being currently pregnant. I also include state fixed effects. 
Table 6: The Impact of Child Gender on Other Household Outcome Variables

Panel A: Have own money and a savings account, allowed to go somewhere without permission

\begin{tabular}{cccccc} 
& have own money & have savings account & go to market & health facility & go outside village \\
\hline Son (no controls) & -0.0125 & $0.0364^{* *}$ & $0.0445^{* *}$ & 0.0345 & 0.0290 \\
& $(0.0221)$ & $(0.0150)$ & $(0.0225)$ & $(0.0219)$ & $(0.0203)$ \\
R-squared & 0.0002 & 0.003 & 0.002 & 0.0013 & 0.0011 \\
son (controls) & -0.0152 & $0.0257^{*}$ & 0.0249 & 0.0149 & 0.0083 \\
& $(0.0206)$ & $(0.0143)$ & $(0.0199)$ & $(0.0204)$ & $(0.0189)$ \\
R-squared & 0.1649 & 0.1418 & 0.2496 & 0.1779 & 0.1803 \\
N & & & & & 1918 \\
mean & 1918 & 1917 & 1918 & 0.3608 & 0.2732 \\
\hline
\end{tabular}

Panel B: allowed to go somewhere only with permission

\begin{tabular}{cccc} 
& go to market & health facility & go outside village \\
\hline Son (no controls) & -0.0320 & -0.0310 & -0.0136 \\
& $(0.0228)$ & $(0.0225)$ & $(0.0220)$ \\
R-squared & 0.001 & 0.001 & 0.0002 \\
Son (controls) & & & 0.0035 \\
R-squared & -0.0168 & -0.0138 & $(0.0211)$ \\
N & $0.0214)$ & $(0.0212)$ & 0.1251 \\
mean & & 0.1528 & 1918 \\
\hline
\end{tabular}

Notes: $* * * \mathrm{p}<0.01, * * \mathrm{p}<0.05, * \mathrm{p}<0.1$

Control variables are: household size, mother's age and the age of the household head, indicator variables for living in a rural area and for each year of mother's schooling, indicator variables for being Hindu, Muslim, a member of the scheduled castes or scheduled tribes (SC and ST, respectively), and for being currently pregnant. I also include state fixed effects. 